\title{
Driving Safety in Adolescents and Young Adults With Type 1 Diabetes
}

\author{
Alissa J. Roberts, ${ }^{1}$ Ashley Moss, ${ }^{1}$ Faisal S. Malik, ${ }^{1}$ Craig Taplin, ${ }^{1}$ Catherine Pihoker, ${ }^{1}$ Irl B. Hirsch, ${ }^{1}$ \\ Kendra Read, ${ }^{1}$ and Joyce P. Yi-Frazier ${ }^{2}$ \\ ${ }^{1}$ University of Washington, Seattle, WA; ${ }^{2}$ Seattle Children's Research Institute, Seattle, WA
}

Adolescent and young adult (AYA) drivers are at high risk for automobile accidents and fatalities (I-3). Unintentional accidents were the leading cause of death in 2017 of individuals aged $15-19$ years in the United States (4). Factors that increase driving safety risk associated with AYA drivers include lack of driving experience, developmental factors such as poor executive function, and propensity for risktaking behaviors (5,6). Furthermore, cognitive abilities such as self-control and emotional regulation are continuing to develop through late adolescence and into young adulthood, making AYA drivers particularly vulnerable to practicing unsafe driving behaviors (7). Brain developmentin particular the prefrontal cortex, which relates to impulse control-is known to continue well into young adulthood, not reaching adult dimensions until the mid2os $(8,9)$.

AYAs with type I diabetes face a unique set of challenges relating to driving safety. Blood glucose fluctuations leading to hypoglycemia can temporarily impair cognitive function (IO-I2) and lead to unsafe driving conditions (I3). Given the safety risks posed by hypoglycemia, the American Diabetes Association (ADA) has made specific recommendations to promote safe driving for individuals with diabetes (I4). The ADA recommends that drivers with type I diabetes measure their blood glucose level before driving and at regular intervals if they are driving for longer than I hour. Individuals with type I diabetes should be counseled to always carry appropriate rapidacting glucose and complex micronutrient snacks. If symptoms of hypoglycemia occur, individuals should immediately stop driving, check their blood glucose, and treat low blood glucose levels. Additionally, driving should only be resumed after achievement of euglycemia and once cognitive functioning has been recovered (i.e., ideally 30-60 minutes after euglycemia is achieved because of concern about delayed cognitive function recovery) (I4). Parents of adolescents with type I diabetes report that their teens are unlikely to adhere to safe driving practices consistently (I5). A recent study of Canadian adolescents with type I diabetes suggests that many do not adhere to driving safety recommendations around glucose monitoring in the context of diabetes management (I6).

AYAs are also at high risk for engaging in behaviors that increase driving risk and contribute to distracted driving and fatalities, including texting while driving and substance use $(17,18)$. Similar to the cognitive impairment seen with hypoglycemia, alcohol or marijuana use also can result in severe sensory and motor impairment, including reduced awareness of external stimulation (19,20). Driving after alcohol or marijuana use increases the risk of motor vehicle accidents (MVAs), and prevalence of driving after use of these substances has been reported to be high among AYAs (2I). Studies have indicated that, in the United States, I2-28\% of AYAs report driving under the influence of alcohol, and $3-\mathrm{II} \%$ report driving under the influence of marijuana $(\mathrm{I} 8,22,23)$. Additionally, use of cell phones and texting are major causes of distracted driving and MVAs (24). According to the Centers for Disease Control and Prevention, $45 \%$ of U.S. high school students report texting while driving (25). Texting while driving has been shown to increase both reaction time while driving and the likelihood of having an MVA (26). To our knowledge, research has yet to examine substance use and texting while driving in AYAs with type I diabetes.

The aim of this study was to examine self-reported diabetesspecific driving practices, hypoglycemia management practices around driving, and substance use and texting while driving in AYAs with type I diabetes.

Corresponding author: Alissa J. Roberts, Alissa.Roberts@seattlechildrens.org

C.T. is currently affiliated with Perth Children's Hospital, Nedlands, WA

This article contains supplementary material online at https://doi.org/10.2337/figshare.12863594.

https://doi.org/10.2337/ds20-0021

(C)2020 by the American Diabetes Association. Readers may use this article as long as the work is properly cited, the use is educational and not for profit, and the work is not altered. More information is available at https://www.diabetesjournals.org/content/license. 


\section{Research Design and Methods}

\section{Participants and Procedures}

The study population included AYAs (aged I5-22 years) seen as a part of an AYA Diabetes Transition Program, which included a pediatric diabetes clinic in a stand-alone pediatric hospital partnered with an adult diabetes care center, between September 2017 and July 20I9. This clinic was located in Washington State. Patients with a clinical diagnosis of type I diabetes who reported driving were eligible to complete the survey examining driving safety behaviors. Surveys were completed electronically on a tablet using the Tonic for Health application (tonicforhealth.com), a Health Insurance Portability and Accountability Act-compliant platform, at each patient's first AYA clinic visit as part of the clinic intake process. All patients who completed the clinical intake process for the AYA clinic during the study period were asked whether they drive, and, if so, they were given the driving safety behavior survey to complete. All aspects of the study followed a protocol approved by the Seattle Children's Research Institute's institutional review board.

\section{Measures/Analysis}

A pediatric multidisciplinary diabetes team experienced in clinical research developed the driving safety behavior survey items based on published ADA driving recommendations (I4) and a literature review. No previous validated survey instruments were available to guide questionnaire development. An initial bank of survey items was developed and reviewed by a team of pediatric endocrinologists, pediatric psychologists, clinical researchers, and adolescent medicine physicians. The final questionnaire explored diabetes management behaviors related to driving safety, as well as general unsafe driving practices (Supplementary Appendix I). Clinical data were obtained via clinic intake forms and chart review. These included AIC at the time of the first AYA visit, insulin delivery method, continuous glucose monitoring (CGM) system use, and demographic data.

Descriptive statistics were used to describe driving behaviors. $\chi^{2}$ Tests or $t$ tests were used to examine differences between driving practices by age, time since diagnosis, sex, and CGM use. For the purposes of this analysis, responses were dichotomized to rarely/never and always/often, where applicable. $\chi^{2}$ Tests for independence (Yates continuity correction) were performed to examine relationships among technology use (i.e., insulin pump and CGM) and driving behaviors. All analyses were conducted using SPSS, v. I9, statistical software.

\section{TABLE 1 Participant Characteristics $(n=101)$}

Age, years

$19.3 \pm 1.4(15.5-22.0)$

\begin{tabular}{lc}
\hline Time since diagnosis, years & $9.4 \pm 4.5(0.1-19.9)$ \\
\hline A1C, \% & $8.4 \pm 1.7(5.4-14)$ \\
\hline PAID-T score (diabetes distress) & $30.1 \pm 13.1(14-78)$ \\
\hline PHQ-9 score (depression) & $4.2 \pm 4.7(0-22)$ \\
\hline Female sex & 45 \\
\hline Race/ethnicity & 76 \\
Non-Hispanic white & 4 \\
Non-Hispanic black & 11 \\
Hispanic & 4 \\
Other & 5 \\
Not stated & 85 \\
\hline Insurance & 14 \\
Private & 1 \\
Medicaid/Medicare & 64 \\
Self-pay & 53 \\
\hline Insulin pump use* & \\
\hline CGM use &
\end{tabular}

Data are mean \pm SD (range) or percentages. *Versus a multiple daily injection regimen. PAID-T, Problem Areas in Diabetes-Teen questionnaire; PHQ-9, nine-item Patient Health Questionnaire depression module.

\section{Results}

One hundred thirty-seven patients completed the intake process in the AYA clinic during the study period. Of those, I05 participants reported driving and completed the driving safety behavior survey as part of their clinical intake. Four patients declined participation; thus, the study sample was IoI participants, for whom descriptive data are presented in Table I. Forty-five percent of participants were female, with an average age of 19.3 years (SD I.4). Fifty-three percent of participants used CGM, and $64 \%$ used an insulin pump. The average duration of type I diabetes was 9.4 years (SD 4.5), and the average AIC was $8.4 \%$ (SD I.7).

Diabetes-specific driving behaviors are presented in Table 2. Forty-two percent of participants reported checking their blood glucose level rarely or never within 30 minutes before driving. If they had a glucose level $<70 \mathrm{mg} / \mathrm{dL}$ before driving, $53.5 \%$ reported waiting until a recheck glucose level (after treatment) was $\geq 70 \mathrm{mg} / \mathrm{dL}$ before driving. When looking at all participants, 50.5\% reported pulling over their vehicle, treating hypoglycemia, and waiting until their glucose was $\geq 70 \mathrm{mg} / \mathrm{dL}$ when they experienced hypoglycemia while driving or were alerted that they were becoming hypoglycemic via CGM. Sixty-four percent reported always having a source of rapid-acting glucose available when driving. 


\section{TABLE 2 Driving Safety Behaviors}

\begin{tabular}{|c|c|c|c|}
\hline Behavior & Rarely/Never & Often & Always \\
\hline Do you check blood glucose within 30 minutes before driving? & 41.6 & 42.6 & 15.8 \\
\hline \multirow{2}{*}{$\begin{array}{l}\text { Do you have a source of rapid-acting glucose available when } \\
\text { driving? }\end{array}$} & 8.9 & 26.7 & 64.4 \\
\hline & $<5$ Times & 5-10 Times & $\geq 11$ Times \\
\hline $\begin{array}{l}\text { How often have you had hypoglycemia (blood glucose }<70 \mathrm{mg} / \mathrm{dL} \text { ) } \\
\text { at any time in the past month? }\end{array}$ & Never & 1-5 Times & $\geq 6$ Times \\
\hline $\begin{array}{l}\text { How often have you had hypoglycemia (blood glucose }<70 \mathrm{mg} / \mathrm{dL} \\
\text { or symptomatic) while driving in the past month? }\end{array}$ & 53.5 & 43.6 & 3.0 \\
\hline \multicolumn{3}{|l|}{ Have you ever had a car accident? } & 36.6 \\
\hline \multicolumn{3}{|l|}{ Have you ever had a car accident while glucose was low? } & 0 \\
\hline \multicolumn{3}{|l|}{ Do you wear a medical alert? } & 38.6 \\
\hline \multicolumn{3}{|c|}{ If hypoglycemia occurs when you are about to drive, do you treat and wait until you are normoglycemic to drive? } & 53.5 \\
\hline \multicolumn{3}{|c|}{ If hypoglycemia occurs while driving, do you pull over, treat, and wait until you are normoglycemic to drive? } & 50.5 \\
\hline
\end{tabular}

Data are \%.

Nearly half of participants (46.6\%) reported having a low blood glucose while driving in the past month. Of those who reported having hypoglycemia while driving, $42.6 \%$ reported treating and waiting for euglycemia when this occurred. Approximately $8 \%$ of participants reported an episode of severe hypoglycemia (seizure or need for assistance) in the past year. No participants reported having an MVA while hypoglycemic.

Participants who experienced hypoglycemia while driving had significantly longer durations of diabetes (II.2 \pm 3.9 years) than those who reported not experiencing hypoglycemia while driving $(8.0 \pm 4.6$ years) $[\mathrm{t}(99)=-3.82$, $P<$ o.oI]. Participants who continued driving while experiencing hypoglycemia also had a longer mean duration of diabetes (I0.33 \pm 4.62 years) compared with those who waited to confirm euglycemia before driving $(8.58 \pm 4.25$ years) $[\mathrm{t}(99)=\mathrm{I} .98, P<0.05]$. There was a significant difference in age for those who reported checking their glucose before driving (I9.I \pm I.4 years) and those who do not $(19.7 \pm \mathrm{I} .2$ years $)[\mathrm{t}(99)=2.32, P<0.05]$. There was also a significant difference in age for those who chose not to recheck glucose after treatment and confirm euglycemia when experiencing hypoglycemia before driving ( $19.7 \pm \mathrm{I} .3$ years) compared with those who waited for euglycemia (I9.I \pm I.4 years) $[\mathrm{t}(99)=2.35, P<0.05]$. There were no significant differences in driving behaviors across sex. A trend for the association between pump status and checking blood glucose 30 minutes before driving was observed $\left[\chi^{2}(\mathrm{I}, n=\right.$ IOI $)=3.65, P=0.06, \varphi=0.2 \mathrm{I}($ small effect $)]$. There were no other significant associations with technology and driving behaviors.

General driving-related risk behaviors were examined. Nine percent reported driving within a few hours of consuming alcohol, $5.9 \%$ reported driving while feeling the effects of alcohol or other drugs, I0.9\% reported driving within a few hours of using marijuana, and $39.6 \%$ reported texting while driving (7.9\% daily, I4.9\% few times a week, and $16.8 \%$ few times a month).

\section{Discussion}

In this study, approximately half of AYAs with type I diabetes reported experiencing hypoglycemia while driving within the past month. More than one-third of AYAs with type I diabetes reported not always having a source of rapidacting glucose available to treat hypoglycemia while 
driving, and $>40 \%$ shared that they do not check their glucose level before driving. Furthermore, only about half of participants reported confirming normoglycemia before initiating or reinitiating driving after hypoglycemia. These results suggest that many AYAs with type I diabetes need to be better counseled about avoiding, detecting, and treating hypoglycemia while driving.

The importance of taking measures to prevent hypoglycemia while driving and mitigating associated risks has been well described (27-29). For example, in one prospective study of adult drivers with type I diabetes, $52 \%$ of participants reported at least one hypoglycemia-related driving mishap in a I2-month period (28). Our finding that a significant percentage of AYAs with type I diabetes experience hypoglycemia while driving demonstrates the need for clinical teams to routinely query AYAs about recent experiences concerning hypoglycemia while driving. Frequent in-clinic assessment of driving risk, including asking about driving and hypoglycemia history, as well as behaviors influencing driving risk (diabetes- and nondiabetes-related), is likely prudent to direct education and resources to those at highest risk for driving mishaps.

Similar to studies of U.S. adults with type I diabetes, many AYAs with type I diabetes in our study reported unsafe diabetes management practices in the context of driving (I6,30). In addition, although our study included both adolescents and young adults in the United States, it is worth noting that our results regarding rates of blood glucose level checks before driving and episodes of hypoglycemia while driving were almost identical to those found with Canadian adolescent licensed drivers (I6).

Our study highlights the lack of adherence to safe diabetes driving practices in the United States and suggests that there is a need for incorporating improved education to increase safe driving practices among AYAs with type I diabetes. Methods that have been used to encourage behavior change in adolescents, such as motivational interviewing or family-based interventions, may be considered when designing an intervention to improve driving safety in this population $(31,32)$.

Rates of marijuana use before driving (I0.5\%) and texting while driving $(\sim 40 \%)$ among AYAs with type I diabetes in this study were similar to those in the general AYA population (3-II\% endorse marijuana use and driving and $45 \%$ endorse texting while driving) $(18,21,22,25)$. However, the rate of driving after alcohol use was lower than has been reported in other studies of AYAs without type I diabetes. It is estimated that nearly one-fourth of AYAs in the general population drive after consuming alcohol, whereas only about IO\% of AYAs with type I diabetes in our study reported doing so (23). This finding suggests there is likely some effective education and awareness around the impact of alcohol on blood glucose, specifically that alcohol contributes to acute and delayed-onset hypoglycemia and can also exacerbate the effects of hypoglycemia $(33,34)$.

The detrimental cognitive impact of hypoglycemia and alcohol on driving can be cumulative, and thus, alcohol consumption before driving is incredibly risky for individuals with type I diabetes (34). Although our study suggests that there is some understanding of the consequences of alcohol consumption in the AYA population, there are still some AYAs with type I diabetes who do drive after consuming alcohol. Given that many AYAs with type I diabetes often fail to engage in behaviors that would prevent or adequately treat hypoglycemia before and during driving (e.g., not monitoring glucose, not bringing rapid-acting carbohydrates, and not pulling over if hypoglycemia occurs), the compounded impact of alcohol use and hypoglycemia on cognition and driving ability places these adolescents at particularly high risk for driving mishaps.

Legislation focused on banning texting while driving has decreased the impact of this behavior on MVAs (35). Just before initiation of this study, the state of Washington passed a law that made it illegal to talk or send text messages on a wireless device while driving. Washington State also has graduated driver licensing laws for teenage drivers, a practice that is associated with reduction of alcohol use and risky driving behaviors in youth (36). Despite these measures, nearly $40 \%$ of the participants in this study reported texting while driving, and a higher number of AYAs might be engaging in risky driving behaviors in states where such legislation and licensing requirements are not in place.

Few associations were observed among demographic and clinical factors and specific driving behaviors, suggesting that unsafe driving practices may be universal in this population. We did find that AYAs with a longer duration of type I diabetes were more likely to experience hypoglycemia when driving and less likely to stop driving when experiencing hypoglycemia. This finding suggests that AYAs who have had a longer duration of diabetes may be at increased risk for unsafe driving practices and could be a focus of clinical and educational interventions to improve safety around driving.

Of note, technology use did not significantly affect driving practices; however, this finding may simply reflect the need for a larger sample size to explore the benefits of technology 
use on prevention and detection of hypoglycemia in the context of driving. Furthermore, CGM and insulin pump technology continued to evolve throughout the study period and will continue to do so, which may affect how these tools are used to improve driving safety. CGM use in particular has been shown to reduce hypoglycemia risk and thus could be particularly effective in enhancing driving safety (37,38). However, children and adolescents have been found to have a high level of attrition in CGM use over time, and sustained use is more difficult in this population (38).

This study has limitations. Given that self-reported data were used, the study may suffer from response and social desirability bias. Participants may have underreported unsafe driving practices because the surveys were completed in the clinical setting, and participants were aware that the clinical team would have access to their responses. However, the need to promote improved driving safety practices in AYAs with type I diabetes would remain, even without such biases. Furthermore, the survey instrument developed to assess driving behaviors among AYAs with type I diabetes has not yet been validated as a research or clinical tool. Finally, data collected as a part of this study were from a convenience sample in the context of an AYA diabetes transition clinic visit. Therefore, these data may not be representative of driving behaviors of the general population of AYAs with type I diabetes.

\section{Conclusion}

Results from this study demonstrate that hypoglycemia while driving is common and that AYAs with type I diabetes are not optimally implementing safe driving practices, particularly around prevention, detection, and treatment of hypoglycemia. Furthermore, like the general AYA population, many AYAs with type I diabetes report unsafe behaviors around substance use before driving and texting while driving. Given that instilling good driving practices in young drivers can translate into improved adherence in adulthood, further education and other behavioral interventions to promote safe driving practices among AYAs with type I diabetes should be pursued.

\section{ACKNOWLEDGMENTS}

The authors thank Michael Pascual for his contributions to data acquisition and Dr. Raina Voss for her contributions to initial study design.

\section{FUNDING}

This work was supported by the Forest and Sequoia Foundations. Dr. Malik's time was supported in part by a K23 Career Development Award from the National Institute of Diabetes and Digestive and Kidney Diseases of the National Institutes of Health (DK119465).

\section{DUALITY OF INTEREST}

No potential conflicts of interest relevant to this article were reported.

\section{AUTHOR CONTRIBUTIONS}

A.J.R. conceptualized and designed the study, coordinated and supervised data collection, and drafted the initial manuscript. A.M. and F.S.M. contributed to the data acquisition and analysis plan and interpretation. C.T., C.P., I.B.H., K.R., and J.P.Y.-F. conceptualized and designed the study. All authors reviewed, revised, and approved the final manuscript. A.J.R. is the guarantor of this work and, as such, had full access to all the data in the study and takes responsibility for the integrity of the data and the accuracy of the data analysis.

\section{PRIOR PRESENTATION}

Preliminary abstract data from this study were presented in poster format at the American Diabetes Association's 79th Scientific Sessions, 7-11 June 2019, San Francisco, CA.

\section{REFERENCES}

1. Gonzales MM, Dickinson LM, DiGuiseppi C, Lowenstein SR. Student drivers: a study of fatal motor vehicle crashes involving 16-yearold drivers. Ann Emerg Med 2005;45:140-146

2. Alderman EM, Johnston BD; Committee on Adolescence; Council on Injury, Violence, and Poison Prevention. The teen driver. Pediatrics 2018;142:e20182163

3. National Highway Traffic Safety Administration. Traffic safety facts: 2016 data: young drivers. Available from https:// crashstats.nhtsa.dot.gov/Api/Public/ViewPublication/812498. Accessed 20 August 2020

4. Heron M. Deaths: leading causes for 2017. Natl Vital Stat Rep 2019;68:1-77

5. Shope JT, Bingham CR. Teen driving: motor-vehicle crashes and factors that contribute. Am J Prev Med 2008;35(Suppl.): S261-S271

6. Walshe EA, Ward McIntosh C, Romer D, Winston FK. Executive function capacities, negative driving behavior and crashes in young drivers. Int J Environ Res Public Health 2017;14:1314

7. Dahl RE. Biological, developmental, and neurobehavioral factors relevant to adolescent driving risks. Am J Prev Med 2008; 35(Suppl.):S278-S284

8. Luciana M. Adolescent brain development in normality and psychopathology. Dev Psychopathol 2013;25:1325-1345

9. Giedd JN. Structural magnetic resonance imaging of the adolescent brain. Ann N Y Acad Sci 2004;1021:77-85

10. Gejl M, Gjedde A, Brock B, et al. Effects of hypoglycaemia on working memory and regional cerebral blood flow in type 1 diabetes: a randomised, crossover trial. Diabetologia 2018;61:551-561

11. Graveling AJ, Deary IJ, Frier BM. Acute hypoglycemia impairs executive cognitive function in adults with and without type 1 diabetes. Diabetes Care 2013;36:3240-3246

12. Gonder-Frederick LA, Zrebiec JF, Bauchowitz AU, et al. Cognitive function is disrupted by both hypo- and hyperglycemia in schoolaged children with type 1 diabetes: a field study. Diabetes Care 2009;32:1001-1006

13. Graveling AJ, Frier BM. Driving and diabetes: problems, licensing restrictions and recommendations for safe driving. Clin Diabetes Endocrinol 2015;1:8

14. Lorber D, Anderson J, Arent S, et al.; American Diabetes Association. Diabetes and driving. Diabetes Care 2014;37(Suppl. 1): S97-S103

15. Cox DJ, Gonder-Frederick LA, Shepard JA, Campbell LK, Vajda KA. Driving safety: concerns and experiences of parents of adolescent drivers with type 1 diabetes. Pediatr Diabetes 2012;13:506-509

16. Potter K, Virtanen $\mathrm{H}$, Stewart $\mathrm{F}$, et al. Exploring knowledge and safety practices for driving in youth with type 1 diabetes. Can J Diabetes 2020;44:169-174.e2 
17. Hayashi Y, Rivera EA, Modico JG, Foreman AM, Wirth O. Texting while driving, executive function, and impulsivity in college students. Accid Anal Prev 2017;102:72-80

18. Greene KM, Hedstrom AM, Murphy ST. Driving/riding after alcohol and marijuana use among young adults: is residing with family protective? Traffic Inj Prev 2019;20:679-684

19. Irwin C, ludakhina E, Desbrow B, McCartney D. Effects of acute alcohol consumption on measures of simulated driving: a systematic review and meta-analysis. Accid Anal Prev 2017;102:248-266

20. Bondallaz P, Favrat B, Chtioui H, Fornari E, Maeder P, Giroud C. Cannabis and its effects on driving skills. Forensic Sci Int 2016; 268:92-102

21. Whitehill JM, Rivara FP, Moreno MA. Marijuana-using drivers, alcohol-using drivers, and their passengers: prevalence and risk factors among underage college students. JAMA Pediatr 2014;168: 618-624

22. Azofeifa A, Rexach-Guzmán BD, Hagemeyer AN, Rudd RA, SauberSchatz EK. Driving under the influence of marijuana and illicit drugs among persons aged $\geq 16$ years: United States, 2018. MMWR Morb Mortal Wkly Rep 2019;68:1153-1157

23. Buckley L, Bonar EE, Walton MA, et al. Marijuana and other substance use among male and female underage drinkers who drive after drinking and ride with those who drive after drinking. Addict Behav 2017;71:7-11

24. Wilson FA, Stimpson JP. Trends in fatalities from distracted driving in the United States, 1999 to 2008. Am J Public Health 2010; 100:2213-2219

25. Olsen EO, Shults RA, Eaton DK. Texting while driving and other risky motor vehicle behaviors among US high school students. Pediatrics 2013;131:e1708-e1715

26. Yannis G, Laiou A, Papantoniou P, Christoforou C. Impact of texting on young drivers' behavior and safety on urban and rural roads through a simulation experiment. J Safety Res 2014;49:25-31

27. Cox DJ, Penberthy JK, Zrebiec J, et al. Diabetes and driving mishaps: frequency and correlations from a multinational survey. Diabetes Care 2003;26:2329-2334

28. Cox DJ, Ford D, Gonder-Frederick L, et al. Driving mishaps among individuals with type 1 diabetes: a prospective study. Diabetes Care 2009;32:2177-2180
29. Cox DJ, Gonder-Frederick L, Clarke W. Driving decrements in type I diabetes during moderate hypoglycemia. Diabetes 1993;42: 239-243

30. Graveling AJ, Warren RE, Frier BM. Hypoglycaemia and driving in people with insulin-treated diabetes: adherence to recommendations for avoidance. Diabet Med 2004;21: 1014-1019

31. Desai $\mathrm{N}$. The role of motivational interviewing in children and adolescents in pediatric care. Pediatr Ann 2019;48: e376-e379

32. Connell AM, Dishion TJ, Yasui M, Kavanagh K. An adaptive approach to family intervention: linking engagement in family-centered intervention to reductions in adolescent problem behavior. J Consult Clin Psychol 2007;75:568-579

33. Richardson $T$, Weiss $M$, Thomas $P$, Kerr D. Day after the night before: influence of evening alcohol on risk of hypoglycemia in patients with type 1 diabetes. Diabetes Care 2005;28: 1801-1802

34. Cheyne EH, Sherwin RS, Lunt MJ, Cavan DA, Thomas PW, Kerr D. Influence of alcohol on cognitive performance during mild hypoglycaemia; implications for type 1 diabetes. Diabet Med 2004; 21:230-237

35. Ferdinand AO, Aftab A, Akinlotan MA. Texting-while-driving bans and motor vehicle crash-related emergency department visits in 16 US states: 2007-2014. Am J Public Health 2019;109: 748-754

36. Cavazos-Rehg PA, Housten AJ, Krauss MJ, et al. Selected state policies and associations with alcohol use behaviors and risky driving behaviors among youth: findings from Monitoring the Future study. Alcohol Clin Exp Res 2016;40:1030-1036

37. Oliver N, Gimenez M, Calhoun P, et al. Continuous glucose monitoring in people with type 1 diabetes on multiple-dose injection therapy: the relationship between glycemic control and hypoglycemia. Diabetes Care 2020;43:53-58

38. Juvenile Diabetes Research Foundation Continuous Glucose Monitoring Study Group. Effectiveness of continuous glucose monitoring in a clinical care environment: evidence from the Juvenile Diabetes Research Foundation continuous glucose monitoring (JDRF-CGM) trial. Diabetes Care 2010;33: $17-22$ 